Fecha de recepción: diciembre 2018 Fecha de aceptación: marzo 2019 Versión final: junio 2019

\section{Las heroínas transmediales de Alba Cromm, de Vicente Luis Mora, y La muerte me da, de Cristina Rivera Garza}

Andrés Olaizola *

Resumen: En los últimos años, cada vez más proyectos, objetos, programas, artefactos, obras, textos pertenecientes a la esfera cultural poseen, en alguna o en todas las etapas del proceso productivo, algún componente transmedial. Prácticamente, no quedan actores de la cultura y la comunicación "que no estén pensando su producción en términos transmediáticos, desde la ficción hasta el documental, pasando por el periodismo, la publicidad y la comunicación política" (Scolari, 2014). En lo que respecta a la industria audiovisual, por ejemplo, "transmedia" se ha convertido en la "palabra mágica" de cualquier proyecto de media o gran envergadura; de hecho, "en algunos momentos parece como si ya no se pudiese hacer algo que se desarrolle en un único medio" (Tubau, 2011).

El sistema de la literatura, por su parte, también ha integrado a la transmedialidad como un elemento o proceso estético más. El relato, pero también una misma estética, retórica o temática, se extienden más allá de los márgenes del texto literario hacia otros medios, cada uno de los cuales no pierde su autonomía y especificidad. A su vez, en la transmedialidad también se articulan "modos de afectación recíproca y procesual entre medios, lenguajes y tecnologías", los cuales desestabilizan fuertemente sus espacios de origen (Kozak, 2015): los textos literarios, que muchas veces funcionan como ventanas de inicio, resultan transformados en el proceso transmedial.

En el siguiente artículo, se analizará la transmedialidad en dos novelas contemporáneas en español: La muerte me da (2007), de la mexicana Cristina Rivera Garza; y Alba Cromm (2010), del español Vicente Luis Mora. Además de detallar el funcionamiento del proceso transmedial, se hará especial hincapié en cómo éste se establece como un componente más en la conformación de las heroínas de las historias.

Palabras claves: transmedialidad - Narrativas transmedia - Narrativas Tecnológicas - Escrituras Digitales - Blogs - Literatura del siglo XXI - Literatura Mexicana - Literatura Española - Rivera Garza - Mora.

[Resúmenes en inglés y portugués en las páginas 76 - 78]

${ }^{(*)}$ Licenciado en Letras (UBA), Profesor Universitario en Letras (UP), Magíster en Educación Superior (UP). Se encuentra realizando su doctorado en Literatura (UBA) y su tema de investigación es el apropiacionismo y la transmedialidad en las narrativas tecnológicas del siglo XXI. Docente-investigador de la Facultad de Diseño y Comunicación de la Universidad de Palermo. Profesor en distintos Institutos de Formación Docente de la Ciudad de Buenos Aires. 


\section{Lo transmedial en el panorama cultural-artístico contemporáneo}

En los últimos años, cada vez más proyectos, objetos, programas, artefactos, obras, textos pertenecientes a las esferas artística y cultural poseen, en alguna o en todas las etapas del proceso productivo, algún componente transmedial. Prácticamente, no quedan actores de la cultura y la comunicación "que no estén pensando su producción en términos transmediáticos, desde la ficción hasta el documental, pasando por el periodismo, la publicidad y la comunicación política" (Scolari, 2014).

En lo que respecta a la industria audiovisual, por ejemplo, "transmedia" se ha convertido en la "palabra mágica" de cualquier proyecto de media o gran envergadura; de hecho, "en algunos momentos parece como si ya no se pudiese hacer algo que se desarrolle en un único medio" (Tubau, 2011). Prueba de la importancia que la transmedia ha adquirido en la esfera audiovisual es que en Estados Unidos "se ha creado ya la profesión de "productor transmedia»" (Tubau, 2011, p. 232). De acuerdo con el Sindicato de Productores de Estados Unidos, un productor o una productora transmedia es la persona que, a largo plazo, planifica, desarrolla, produce y mantiene la continuidad narrativa del proyecto a través de múltiples plataformas, y es quien crea líneas narrativas originales para las nuevas plataformas (Producers Guild of America, 2010).

A partir de un análisis de tres manuales sobre narrativa transmedia escritos por productores y profesionales del medio, Marie-Laure Ryan (2016) sintetiza los ejes sobre los que opera la retórica de la industria audiovisual sobre la transmedia: elogio hiperbólico, actitud capitalista, énfasis en "darle a la gente lo que quiere" y centralidad de la interactividad. El sistema de la literatura, por su parte, también ha integrado a la transmedialidad como un elemento o proceso estético más. El relato, pero también una misma estética, retórica o temática, se extienden más allá de los márgenes del texto literario hacia otros medios, cada uno de los cuales no pierde su autonomía y especificidad. A continuación, mencionaremos algunos ejemplos que nos ayudarán a delinear un panorama hispánico de la transmedia "de origen literario" (Sánchez Aparicio, 2014), es decir, aquella que posee a un texto literario como punto de entrada o ventana de inicio de todo el sistema transmedia. Alice Pantel (2014) señala como uno de los primeros antecedentes a la novela Mzungo (1996), de Luis Goytisolo, que incluía un CD-ROM con varios videojuegos. Será sobre todo a partir del año 2005 cuando varios libros impresos de autoras y autores hispanoamericanos empleen otros medios para ampliar su universo ficcional.

La "trilogía Nocilla", conformada por las novelas Nocilla Dream (2006), Nocilla Experience (2008) y Nocilla Lab (2009), de Agustín Fernández Mallo, se prolongó en actuaciones poéticas en vivo y aún hoy se sigue extiendo a través de un video de 60 minutos alojado en la plataforma Vimeo. Fernández Mallo vuelve a ir más allá de las páginas impresas del libro en El hacedor (de Borges), remake (2011), en la que articula algunos de los capítulos con breves videos casi experimentales subidos a su canal personal de YouTube (nocilladream). El Dorado (2008), de Robert Juan-Cantavella, tenía un sitio web llamado Punkjournalism en donde se recopilaban varios documentos que no aparecían en la versión impresa de la novela y que correspondían a ciertas páginas del libro (Pantel, 2014). 
Reinaldo Laddaga ejercita de curador de Cosas que un mutante debe saber (2013), un libroobjeto que, a través de 55 relatos acompañados de ilustraciones y 55 piezas sonoras, oficia de suerte de continuación de Cuentos breves y extraordinarios (1956), de Jorge Luis Borges y Adolfo Bioy Casares.

Diario de un bebedor de petróleo (2015), de Juan José Mendoza, es un poemario que viene acompañado por un CD llamado DBP, en el cual el músico experimental Alan Courtis realiza un tratamiento sonoro de varios poemas leídos por el propio Mendoza.

Los anteriores ejemplos propician algunas coordenadas que nos permiten esbozar una cartografía de la narrativa transmedia en literatura impresa escrita en español. En trabajos recientes (Olaizola, 2018, 2019), hemos avanzado hacia la conceptualización de un corpus de textos narrativos hispanoamericanos publicados en formato impreso a partir del siglo XXI que proponemos denominar "narrativas tecnológicas" o "tecnonarrativas". "Narrativas tecnológicas" es una elaboración relacionada con la noción de "poéticas tecnológicas", desarrollada por Claudia Kozak $(2009,2011,2014,2015)$, y a partir de las consideraciones sobre "el giro tecnológico", realizadas por Juan José Mendoza (2011).

Las poéticas tecnológicas, las tecnopoéticas, son poéticas (obras, proyectos, no-obras, ideas, personas, programas artísticos) que ponen de relieve la confluencia entre arte y tecnología, que "asumen en cada momento el entorno técnico del que son parte y actúan en consecuencia" (Kozak, 2015, p. 10). De acuerdo con Kozak (2015), las tecnopoéticas no son unívocas con respecto a la relación entre arte y tecnología, sino que en su interior es posible encontrar desde posicionamientos totalmente acríticos y laudatorios, hasta la intervención, el desvío y la resistencia, pasando por posturas intermedias, como el reciclado. A su vez, en tanto el fenómeno técnico/tecnológico es un fenómeno político, ya que implica cierta historia y construcción social hegemónica del sentido de lo tecnológico, las poéticas tecnológicas también son políticas (p. 197).

Las "narrativas tecnológicas" del siglo XXI evidencian una interrelación estrecha entre literatura y tecnología, la cual se daría a partir de dos maneras: la primera de ellas consiste en que varias de las "narrativas tecnológicas" se extienden más allá del formato libro impreso y continúan en y a través de otro medios o soportes (blogs, páginas Web, videos, libros impresos y digitales, presentaciones de PowerPoint, etc.), con lo que desarrollan un sistema transmedia (Kozak, 2015; Ryan, 2013); la segunda manera se basa en que en estas narrativas se evidencian estrategias de asimilación de temáticas, retóricas, formas de narrar, estructuras formales, modos de representación procedentes de lo tecnológico, de las pantallas, de los entornos digitales interconectados, dinámicas que pueden entenderse a partir del principio de transcodificación (Manovich, 2006).

Sobre estas conceptualizaciones, el presente artículo analizará la transmedialidad en dos narrativas tecnológicas del siglo XXI: La muerte me da (2007), de la mexicana Cristina Rivera Garza; y Alba Cromm (2010), del español Vicente Luis Mora. Además de detallar el funcionamiento del sistema transmedia, se hará especial hincapié en cómo éste se establece como un componente más en la conformación de las heroínas de las historias. 


\section{Transficcionalidad y transmedialidad}

En la introducción, hemos hecho una breve referencia a qué entendemos por transmedia. Antes de empezar con el análisis de las novelas, quisiéramos dedicar esta sección a detallar más profundamente este concepto.

Un primer acercamiento al concepto de transmedia nos lo puede proporcionar Claudia Kozak (2015), quien repasa las diversas genealogías y usos de la noción. Para comenzar el recorrido, explica que lo transmedial hace referencia "a algún tipo de transferencia de elementos entre un medio y otro sin que cada uno de ellos pierda su especificidad; desde esa perspectiva se analiza por ejemplo cómo un mismo tópico, estética, discurso aparece en medios diversos" (p. 256).

Sobre la base de la primera definición que revisa Kozak, cuya generalidad y síntesis permite ser aplicada en diferentes áreas de la esfera artística y cultural, podemos avanzar hacia una conceptualización de la transmedialidad más específica al sistema literario. En este marco, podemos destacar a Ryan (2013), quien emplea los conceptos narratológicos de "mundo de la historia" (storyworld) y transficcionalidad para definir a la narrativa transmedia.

El "mundo de la historia" es una representación mental que se construye durante la lectura/visionado/juego con el texto narrativo, es un modelo dinámico de situaciones en continua evolución. Específicamente, el "mundo de la historia" se puede definir a partir de un componente estático que precede a la historia (un inventario de las y los existentes -especies, instituciones sociales, objetos, personajes que habitan en el mundo-, un folklore que se relaciona con las y los existentes, un espacio con determinados rasgos topográficos, un conjunto de leyes naturales, un conjunto de leyes sociales y valores) y de un componente dinámico que captura el desarrollo de los eventos (eventos físicos que ocasionan cambios en las y los existentes; eventos mentales que le brindan significado a los eventos físicos, afectan las relaciones entre los personajes y ocasionalmente alteran el orden social).

Ryan sostiene que la noción de "mundo de la historia" es central para la narrativa transmedia, ya que es lo que permite cohesionar los diversos textos del sistema. La relación que establece un mundo a través de muchos textos se define como transficcionalidad (p. 365). Específicamente, Ryan explica que la transficcionalidad es la migración de entidades ficcionales (personajes, lugares imaginarios, mundos completos, etc.) a través de diferentes textos, los cuales pueden pertenecer a un mismo medio, usualmente la narrativa escrita de ficción. Desde este planteo, la narrativa transmedia es un caso específico de transficcionalidad, es decir, una transficcionalidad que opera a través de diferentes medios (pp. 365-366). En un sistema transmedia, se pueden establecer cuatro tipos de relaciones entre los textos/ documentos: expansión, modificación, transposición y citación.

La relación de expansión, la más usual en los proyectos transmediales, consiste en extender los límites, la dimensión del mundo original agregando más existentes, a través de una serie de operaciones: transformar a personajes secundarios en protagonistas de la historia, hacer que personajes visiten nuevas regiones del mundo, y prolongar la línea de tiempo de la historia original por medio de secuelas y precuelas.

.La transposición es la relación que conserva el mismo argumento del mundo, pero lo transporta a diferentes locaciones temporales o espaciales. Tanto la modificación como 
la transposición se refieren a mundos que están relacionados con el original, pero que en definitiva son diferentes.

Finalmente, la relación de citación se observa en las parodias: un elemento importado no se integra al "mundo de la historia" y ello provoca un efecto de disonancia e incongruencia. La citación cuestiona la unidad y la autonomía del mundo original, con lo cual crea una distancia irónica que previene la inmersión.

Varios autores (Jenkins, 2009; Gallego Aguilar, 2011; Nallar, 2016) subrayan que la narrativa transmedia no se debe confundir con la adaptación, aunque los dos procesos tienden puentes entre diferentes medios. Ryan (2016) coincide en que la narrativa transmedia no es lo mismo que la adaptación, pero subraya que es erróneo excluir ésta última de los universos transmedia, porque eliminaría la redundancia de estos sistemas.

Para Ryan (2016), la repetición, el "recuento" de un mismo material en diferentes medios es la columna vertebral de la narrativa transmedia, y las audiencias las aman, ya que les permite revivir las historias y volver a visitar su mundo ficcional de una forma distinta. Las franquicias transmedia usualmente presentan muchos solapamientos entre los documentos que la integran, pero como cada medio tiene un poder expresivo diferente, ningún "recuento" va a transmitir exactamente la misma información.

A partir de estas consideraciones, Ryan (2016) postula describir a los sistemas transmedia como una combinación de transficcionalidad y adaptaciones.

\section{La muerte me da}

La muerte me da (2007), de Cristina Rivera Garza, se presenta como parte central de un sistema transficcional y transmedia y, paradójicamente, la novela en sí posee escasas referencias a lo tecnológico en su trama.

En 2007, antes de la publicación de la novela, la editorial mexicana Bonobos Editores publicó un poemario llamado La muerte me da, de la autora desconocida Anne-Marie Bianco. Ese mismo texto se incluirá después en la novela de Rivera Garza, en la cual se indica que pertenece a la asesina serial de la historia.

Por otro lado, un personaje secundario de La muerte me da, la misteriosa Increíblemente Pequeña, protagonizó en el blog de Rivera Garza, No hay tal lugar. U-tópicos contemporáneos, siete episodios de una fotonovela de carácter lírico que investigaba en distintas formas de diseño y de escritura, entre ellas la del PowerPoint (CRISTINA RIVERA GARZA, 2011). Finalmente, la protagonista de La muerte me da, la Detective, volverá a aparecer en los relatos de La frontera más distante (2008), en la novela El mal de taiga (2012), y en dos entregas de la fotonovela de Increíblemente Pequeña: "Las aventuras de la Increíblemente Pequeña y el extraño caso de la intemperie que mata" (junio de 2011), "Las aventuras de la Increíblemente Pequeña y el momento en que el alma se hace demasiadas preguntas" (julio de 2011). En la novela, una serie de hombres castrados aparecen en distintos puntos de la ciudad. La asesina deja como pistas fragmentos de textos de Pizarnik en las escenas de los crímenes y envía al personaje de Cristina Rivera Garza (informante y consultora de la detective que lleva el caso) cartas, notas y hasta sus propios poemas. 
La muerte me da parte de los géneros de la novela policial y del.-, históricamente dominados por ambientes y personajes masculinos, para subvertirlos: detective, informante y criminal son mujeres; las víctimas, hombres. Los cuerpos de los hombres son castrados física y simbólicamente, ya que se les seccionó el miembro y son llamados víctimas - "La víctima es siempre femenina" (Rivera Garza, 2007, p. 30)-, con lo cual se establece una continua castración discursiva (Sánchez Becerril, 2013).

El sistema transmedia de La muerte me da expande el mundo de la novela hacia textos de un mismo medio (la literatura impresa, ya sea narrativa o lírica), con lo cual se establece un proceso transficcional, pero también hacia medios digitales, como la fotonovela del blog de Rivera Garza.

Los diferentes medios o plataformas involucrados en un proyecto transmedia atraerán a diferentes segmentos de la audiencia. Por lo tanto, "una buena franquicia transmediática trabaja para atraer a múltiples públicos introduciendo los contenidos de una manera algo distinta en los diferentes medios" (Jenkins, 2008, p. 102). El universo transmedia de La muerte me da emplearía el mismo procedimiento: para alguien interesado en la ficción, la ventana de inicio serán las novelas o los libros de cuentos; para quien se interese por la poesía, lo será el poemario de Bianco; para la audiencia del blog de Rivera Garza, la puerta de entrada consistirá en las reflexiones de la autora o la fotonovela (Sánchez Aparicio, 2014, p. 72).

Entre los documentos del sistema transmedia y transficcional que inicia La muerte me da se establece una relación de expansión, la cual determina que los personajes femeninos (la Detective, la Asesina, Increíblemente Pequeña) inicien una trayectoria temporal, una cronología, a lo largo de la cual adquieren rasgos distintivos para su constitución con existentes del mundo ficticio. A su vez, las potencialidades discursivas, narrativas y estéticas de los diferentes medios van a representar a los personajes de maneras diversas entre sí. A partir de la clasificación de Ryan (2013), en el caso de la Detective, la expansión adquiere la forma de "historias intersticiales", en tanto La frontera más distante (2008), El mal de la taiga (2012) y las entregas de la fotonovela de la Increíblemente Pequeña (2011) funcionan como secuelas de La muerte me da (2007), con lo cual se expande el período de tiempo que cubría la novela de inicio (p. 369). Con los textos transficcionales y transmedia, la Detective sobre todo adquiere un pasado que repercute en el presente ficcional. En El mal de la taiga, la Detective narra cómo un personaje le ofrece trabajo como investigadora privada:

- Hace tiempo que no practico — dije. Aunque en realidad hubiera querido decirle: «iPero es que no sabe usted de mis tantos fracasos?».

El caso de la mujer que desapareció detrás de un remolino.

El caso de los hombres castrados.

El caso de la mujer que dio su mano, literalmente. Sin saberlo.

El caso del hombre que vivió por años dentro de una ballena.

El caso de la mujer que perdió un anillo de jade.

- Mejor así — dijo, como si me hubiera escuchado decir algo más. Luego, sin transición de por medio, colocó un portafolio de piel sobre la mesa y, con unos dedos nerviosos y largos, se dio a la tarea de abrir el candado. (Rivera Garza, 2012, p. 10). 
De forma explícita, la Detective hace referencia a los casos de La muerte me da y a los que se desarrollan en los cuentos "Simple placer. Puro placer", "Estar a mano", "El perfil de él" y "El último signo", de La frontera más distante. Al hacerlo, no solo ancla los hechos sucedidos en la primera novela y en el libro de cuentos como en el pasado de la línea temporal del "mundo de la historia" del sistema transmedia, sino que, como se trata de un relato ulterior, la propia trama de La frontera más distante es pretérita, una pieza más que se suma al universo ficcional.

Si bien el sistema transmedia ubica a determinadas acciones en el pasado, conformando el folklore (Ryan, 2013), los antecedentes, el mythos (Klastrup \& Tosca, 2004) del mundo de la historia, no se brindan coordenadas temporales precisas: los hechos quedan bajo el manto de los recuerdos difusos, suenan como ecos cuyos orígenes no se conocen o no se quieren rastrear. Esta imprecisión se inaugura en la misma La muerte me da, en donde abundan las elipsis, los tiempos muertos, las imágenes fragmentadas. Las referencias temporales son muy escasas: lo único que nos da cierta cronología es el orden de aparición de las víctimas. El relato parece, en parte, discurrir en un presente eterno. Otras veces se insertan analepsis y prolepsis, que contribuyen a desarmar todavía más el orden temporal. Cuando efectivamente el sistema se extiende hacia otros medios, y deja de ser solo transficcional, cuando éste incorpora un lenguaje en donde predomina lo visual y lo sintético, la indefinición temporal se exacerba. Los códigos de la fotonovela, de la historieta y de las diapositivas del PowerPoint configuran una representación, una versión del mundo ficcional que difumina las fechas al responder a una estética que emplea las imágenes fuera de foco, las sombras, las siluetas, para resaltar una atmósfera misteriosa, casi siniestra en el sentido freudiano. La Detective, en tanto existente de esta pieza del mundo ficcional, se incorpora a la representación del tiempo y a la identidad visual del documento. Las acciones de la Detective se desarrollan en una línea temporal que ubica determinados hechos antes del presente del enunciado, pero de forma completamente indeterminada (lo mismo es que algo haya ocurrido el día anterior como hace años), y se enmarcan en convenciones genéricas ligadas al surrealismo y a la tradición del thriller psicológico y la filmografía de David Lynch.

En el caso de la fotonovela que protagoniza la Increíblemente Pequeña, la expansión del "mundo de la historia" de La muerte me da puede entenderse como un tipo de "historia intersticial", ya que, al no especificar referencias temporales, podría funcionar como una precuela o una secuela de la novela original. Por otro lado, también puede clasificarse como una "historia periférica", es decir, una historia que es un "satélite más o menos distante de la macrohistoria”. Ryan (2013) sostiene que las historias periféricas son muchas veces "leyendas" que se relacionan con los objetos o las y los existentes del "mundo de la historia" (p. 369)

Entender a las "historias periféricas" como las que se desarrollan a través de la bruma de lo legendario, donde confluyen saberes, voces, tradiciones, relatos, podría explicar el mundo de la fotonovela de la Increíblemente Pequeña, la cual retoma el planteo onírico que enmarcan sus aventuras en La muerte me da.

La fotonovela, a su vez, pone fin a la duda que flota en La muerte me da, con respecto a si Increíblemente Pequeña existe o si se trata de una alucinación del personaje de Valerio, asistente de la Detective. Con cada entrega de la fotonovela, Increíblemente Pequeña se corporiza, aparece en distintos lugares del "mundo de la historia", establece relaciones con otros y otras existentes del universo ficcional. En términos de Todorov (1981), si en 
La muerte me da la existencia de Increíblemente Pequeña puede explicarse a partir del funcionamiento de lo fantástico, en la fotonovela adquiere sentido como un personaje decididamente maravilloso.

El otro de los medios que forma parte del sistema transficcional y transmedia, el poemario de Anne-Marie Bianco, subraya la hibridación entre "vida real" y literatura que se desarrolla en La muerte me da y, en general, en gran parte de la producción de Rivera Garza. Como ya dijimos, la propia autora aparece como personaje en la novela, es más, durante gran parte de la trama la Detective especula que Rivera Garza es la asesina.

Casi como la materialización de los libros imaginarios de Borges, el poemario de Blanco, a partir del principio de "extracción" que enuncia Jenkins (2009) para las narrativas transmedia, transciende los límites del universo ficcional y se hace presente en el "mundo real". Además de constituirse como parte de un sistema transmedial, La muerte me da es un metatexto que cuestiona la lectura lineal a través del empleo de la fragmentación, en la propia novela, pero también al fragmentar el "mundo de la historia" en otros medios. Y al mismo tiempo, paradójicamente, la novela pone en duda la escritura seccionada (Sánchez Aparicio, 2014, p. 69), porque apela a que las divisiones formales (desde la segmentación en capítulos, pasando por la división del tiempo en pasado/presente/futuro, hasta la distinción de los medios) no permiten un conocimiento completo del universo ficcional.

Para "leer" el relato, las y los existentes ficcionales, el "mundo de la historia", se debe emplear una lectura, podríamos decir, holística, que integre en el proceso de interpretación todos los documentos/textos del sistema transmedia. Así como Valerio seguirá recordando el caso años después de su finalización, a través de varias prolepsis que nos llevan de repente a la vejez del personaje, los lectores tienen que traspasar las fronteras de los medios, de los discursos, del espacio y del tiempo, para recorrer el sistema transmedia de La muerte me da.

\section{Alba Cromm}

En Alba Cromm (2010), Vicente Luis Mora presenta la narración a través del formato, del diseño de una revista de actualidad. El relato de la cacería de un astuto pedófilo y hacker llamado Nemo por parte de la detective Alba Cromm asume la forma de un dossier de la revista machista Upman, por lo tanto, está enmarcado en el diseño de una publicación periódica, con reseñas de series, anuncios publicitarios, artículos con fotografías, etc. El texto de Mora, entonces, además de constituir un sistema transmedia, emplea la multimodalidad en su estructura.

Entre 2005 y 2008, antes de la aparición de la novela Alba Cromm, el personaje de la detective Alba Cromm publicó en su blog Alba Cromm y La vida sin hombres veinticinco post que no aparecen en la versión impresa. La descripción del blog ("Esta bitácora intenta ser un diario bienhumorado y nada feminista sobre la posibilidad de pervivencia e incluso felicidad sin necesitar a esos pequeños bichitos peludos. Es el diario de una mujer sin crisis en la edad de la crisis: casi 40") enmarcaba las reflexiones y las referencias a hechos históricos (la guerra de Kosovo, por ejemplo) que se vertían en las publicaciones, las cuales complementan y complejizan el personaje de Alba Cromm en la novela. 
A partir de las publicaciones en el blog, es posible comprender determinadas posiciones y acciones de Alba Cromm como existente del mundo ficcional, que si bien se dejan deducir por los datos explícitos que se brindan en la novela (ex militar, relación tensa con su familia, etc.) no adquieren tanta claridad como al estar explicada "por sus propias palabras". Este rasgo adquiere más relevancia cuando se recuerda que la voz de Alba está filtrada, editada, manipulada por existentes hombres explícitamente machistas: Ligoy Ritman, director de la revista Upman; y Luis Ramírez, editor del dossier sobre el caso de Nemo en la revista. Además, gran parte de lo conocemos sobre Alba Cromm provienen del cuaderno de notas, de artículos y grabaciones que produce otro existente, el periodista Ezequiel Martínez Cerva. En este universo ficcional, los entornos digitales interconectados representados en la novela son sobre todo los espacios del delito para la heroína, pero como medio autónomo y con existencia fuera de los márgenes del libro son la plataforma para la escritura del yo, para la autor representación de la experiencia personal.

Pantel (2014) destaca cómo muchos y muchas internautas dejaron sus comentarios en distintos posteos, con lo cual se estableció, por lo menos si se asume que los comentarios fueron producidos por usuarios y usuarias reales y no por el mismo Mora, un proceso de retroalimentación, de vinculación entre el documento transmedia y la audiencia.

Los textos producidos por la audiencia evidencian otra de las características de las narrativas transmedia y es que algunos usuarios dejan de ser simplemente consumidores de los productos culturales y se transforman en prosumidores (productores y consumidores), ya que "cooperan activamente en el proceso de expansión transmedia". Los prosumidores se apropian de sus personajes e historias favoritas y escriben una pieza de fan fiction, graban y suben a YouTube una parodia, diseñan memes, etc. Los prosumidores son, en definitiva, “activos militantes de las narrativas que les apasionan" (Scolari, 2013, p. 27).

La narrativa transmedia se potencia por las nuevas tecnologías de información y de comunicación, que apoyan, demandan y generan una "cultura participativa" (Jenkins, Clinton, Purushotma, Robison, Weigel, 2006; Jenkins, 2008) en el marco de una "convergencia mediática" (Jenkins, 2008), la cual, a su vez, depende en gran medida de la participación activa de los usuarios.

Otro de los medios que formaban parte del sistema transmedia de Alba Cromm era el blog del personaje del periodista Luis Ramírez. Las crónicas de Ramírez, como el blog de la detective, estuvieron activos antes de la publicación de la novela, entre los años 2008 y 2009, y ofrecía referencias adicionales sobre la investigación que el periodista realiza sobre el caso de Cromm. Uno de los aspectos más interesantes es que el blog de Ramírez poseía en el blogroll un enlace al blog de Alba Cromm, es decir, una pista migratoria explícita, una ruta de navegación de un proyecto transmedia que marca que cierto tema se desarrollará en otro lugar o medio (Long, 2007; Gallego Aguilar, 2011; Nallar, 2016). Las relaciones entre las y los existentes sobrepasan el "mundo de la historia" y se materializan en el "mundo real". Los dos blogs operan bajo la dinámica de la extracción que habíamos indicado antes con La muerte me da, con la diferencia de que los textos digitales aparecieron antes que el texto impreso; por lo tanto, para gran parte de la audiencia, la puerta de entrada al sistema transmedia de Alba Cromm fueron los blogs de dos existentes de un universo ficcional. Sonia Gómez (2016) agrega otra pieza al sistema transmedia y transficcional de Alba 
Cromm y esta sería los ensayos críticos de Mora en los cuales analiza la evolución del género novelístico bajo la influencia de los nuevos medios de comunicación, y más precisamente Internet. Para Gómez, Alba Cromm es "punto de partida o de llegada, como se considere pertinente" (p. 225), de Pangea. Internet, blogs y comunicación en un mundo nuevo (2006), La luz nueva: singularidades en la narrativa española actual (2007) y El lectoespectador. Deslizamientos entre literatura e imagen (2012). La novela puede ser entendida como la implementación de los postulados teóricos de los ensayos o puede ser parte del corpus literario a partir del cual se desarrollan nuevos argumentos.

\section{Conclusiones}

Las narrativas transmedia de origen literario construyen relatos que continúan más allá del libro impreso, en y a través distintos medios. Entre los medios, los lenguajes, las tecnologías implicadas en un proceso transmedial se establecen modos de afectación recíproca y procesual, los cuales desestabilizan fuertemente sus espacios de origen (Kozak, 2015). En el caso de los sistemas transmedia de La muerte me da y de Alba Cromm, las novelas funcionan como ventanas de inicio $y$, a su vez, resultan transformadas. Los componentes estático y dinámico de sus mundos transmediales mutan, al incluir documentos cronológicamente anteriores y posteriores a la publicación de las novelas.

Los antecedentes, los rumores, el mythos, pero sobre todo las motivaciones de las y los existentes adquieren profundidad a partir de textos intradiegéticos (el blog de Alba Cromm y de Ramírez, el poemario de Bianco existen, se referencian en sus correspondientes mundos ficcionales) y extradiegéticos (la fotonovela de Increíblemente Pequeña y las historias de El mal de la taiga y La frontera más distante no existen como objetos en el "mundo de la historia").

Kozak (2015) también indica que, desde la tradición de la epistemología de la complejidad y de su concepto de transdisciplinariedad, lo "trans" en las artes implicaría el "atravesamiento continuo, fluido y recíproco entre lenguajes y medios para dar lugar a nuevos conocimientos, sensibilidades y afecciones también transformadores" (pp. 257-258). Lo transmedial se vincularía aquí con la transposición entre sistemas semióticos, entre dispositivos. En la transmedialidad se producirían entonces traducciones permanentes, procesos de transcodificación: una forma se desplaza desde un sistema de códigos hacia otros (Bourriaud, 2009). Lo que hemos observado es que en estos sistemas transmedia y transficcionales el pasaje de un sistema semiótico a otro repercute también en la conformación de las y los existentes del universo ficcional, específicamente las heroínas. La transcodificación complejiza a Alba Cromm, a la Detective y a Increíblemente Pequeña, no solo porque permite a la audiencia conocer las motivaciones de sus acciones, sino porque además expande los espacios y la línea temporal a través de las cuales trazan sus trayectorias como existentes ficcionales. Además, las heroínas son traducidas a otras estéticas, formas del relato, modos de composición y retóricas, con lo cual sus posibilidades expresivas se multiplican. 


\section{Lista de Referencias bibliográficas}

Bourriaud, N. (2009). Radicante. Traducción de Michele Guillemont. Buenos Aires: Adriana Hidalgo.

Courtis, A.; Mendoza, J. J. (2015). DBP. Buenos Aires-Bahía Blanca: Vox.

Rivera Garza, C. (2011). Las aventuras de la Increíblemente Pequeña. Recuperado desde http://increiblementepequena-blog.tumblr.com/

Gallego Aguilar, A. F. (2011). Diseño de narrativas transmediáticas. Manizales: Facultad de Artes y Humanidades, Universidad de Caldas.

Gómez, S. (2016). Exonovela: ¿síntoma de una nueva narrativa del siglo XX. Boletín Hispánico Helvético. Dossier El impacto de las nuevas tecnologías sobre los procesos de lectura y escritura, 28 (otoño), pp. 219-231.

Jenkins, H. (2008). Convergence culture: la cultura de la convergencia de los medios de comunicación. Barcelona: Paidós.

Jenkins, H. (2009, September 10). The Aesthetics of Transmedia. Response to David Bordwell (Part One). Confessions of an Aca-Fan. Recuperado desde http://henryjenkins.org/ blog/2009/09/the_aesthetics_of_transmedia_i.html

Jenkins, H.; Clinton, K.; Purushotma, R.; Robinson, A. J.; Weigel, M.. (2006). Confronting the Challenges of Participatory Culture: Media Education for the 21st Century. Chicago: The MacArthur Foundation.

Klastrup, L. \& Tosca, Susana. (2004). Transmedial Worlds: Rethinking Cyberworld Design. 2004 International Conference on Cyberworlds. Recuperado desde http://www.itu.dk/ people/klastrup/klastruptosca_transworlds.pdf

Kozak, C. (2009). Poéticas tecnológicas y escuela. Apuntes sobre canon y experimentación. Propuesta educativa, $\mathrm{N}^{\circ} 32$ (noviembre), pp. 47-53.

Kozak, C. (Comp.). (2011). Poéticas tecnológicas, transdisciplina y sociedad. Actas del Seminario Internacional Ludión/Paragraphe. Buenos Aires: Exploratorio Ludión.

Kozak, C. (Ed.). (2014). Poéticas/políticas tecnológicas en Argentina. 1910-2010. Paraná: La Hendija.

Kozak, C. (Ed.). (2015). Tecnopoéticas argentinas. Archivo blando de arte y tecnología. Buenos Aires: Caja Negra Editora.

Laddaga, R. (Cur.). (2013). Cosas que un mutante debe saber. Más cuentos breves y extraordinarios. Amsterdam: Unsounds.

Manovich, L. (2006). El lenguaje de los nuevos medios de comunicación: la imagen en la era digital. Buenos Aires: Paidós.

Mendoza, J. J. (2011). Escrituras past_. Tradiciones y futurismos del siglo 21. Bahía Blanca: $17 \mathrm{~g}$ Editora.

Mendoza, J. J. (2015). Diario de un bebedor de petróleo. Buenos Aires-Bahía Blanca: Vox. Mora, V. L. (2010). Alba Cromm. Barcelona: Seix Barral.

Mora, V. L. (2012). El lectoespectador. Deslizamientos entre literatura e imagen. Barcelona: Seix Barral. 
Nallar, D. A. (2016). Diseño de juegos en América latina. Teoría y práctica. II. Diseño y narrativa transmedia. Florida: Game Design LA.

Olaizola, A. (2018). Transmedialidad en "tecnonarrativas" hispánicas del siglo XXI. Catálogo de Investigación DC. Recuperado desde https://fido.palermo.edu/servicios_dyc/catalogo_investigacion/detalle_proyecto.php?id_proyecto $=4905 \&$ titulo_ proyectos=Transmedialidad $\% 20$ en $\% 20 \% 93$ tecnonarrativas $\% 94 \% 20$ hisp $\%$ E1 nicas $\% 20$ del\%20siglo\%20XXI

Olaizola, A. (2019). "Monstruos literarios tecnotextuales: Internet y las narrativas tecnológicas del siglo XXI”. Revista Luthor, 39 (febrero). Recuperado desde http://www. revistaluthor.com.ar/spip.php?article207

Pantel, A. (2014). Alba Cromm de Vicente Luis Mora: ¿una novela aumentada? En Marco Kunz y Sonia Gómez. (Eds.). Nueva narrativa española. Barcelona: Linkgua, pp. 155-169. Producers Guild of America. (2010, April 6). PGA Board of Directors Approves Addition of Transmedia Producer to Guild's Producers Code of Credits. Producers Guild of America. Recuperado desde https://www.producersguild.org/news/news.asp?id=39637\&hhSear chTerms $=\% 22$ transmedia $\% 22$

Rivera Garza, C. (2007). La muerte me da. Barcelona: Tusquets.

Rivera Garza, C. (2008). La frontera más distante. Barcelona: Tusquets.

Rivera Garza, C. (2012). El mal de taiga. Barcelona: Tusquets.

Ryan, M.-L. (2013). Transmedial Storytelling and Transfictionality. Poetics Today, 34, 3, pp. 362-388.

Ryan, M.-L. (2016). Transmedia narratology and transmedia storytelling. Artnodes, № 18

Sánchez Aparicio, V. (2014). Y en el principio era Tlön: transmedia de origen literario en las narrativas hispánicas. Caracteres. Estudios culturales y críticos de la esfera digital. Monográfico: Universos transmedia y convergencias narrativas, Vol. 3, №1 (mayo), pp. 61-80.

Sánchez Becerril, I. (2013). Subversión del género en La muerte me da, de Cristina Rivera Garza, y Efectos secundarios, de Rosa Beltrán. En C. Reverte Bernal. (Ed.). Diálogos culturales en la literatura iberoamericana. Actas del XXXIX Congreso del Instituto Internacional de Literatura Iberoamericana. Madrid: Verbum, pp. 1264-1275.

Scolari, C. A. (2013). Narrativas transmedia. Cuando todos los medios cuentan. Barcelona: Deusto.

Scolari, C. A. (2014). Narrativas transmedia: nuevas formas de comunicar en la era digital Anuario AC/E de Cultura Digital 2014, pp. 71-81.

Todorov, T. (1981). Introducción a la literatura fantástica. Traducción de Silvia Delphy. México DF: Premia.

Tubau, D. (2011). El guion del siglo XXI. El futuro de la narrativa en el mundo digital. Barcelona: Alba.

Abstract: In recent years, a growing number of projects, objects, programs, artifacts, works
and texts belonging to the cultural sphere have, at one or at all stages of the production
process, some transmedia component. Practically, there are no actors in the culture and
communication fields "who are not thinking about their production in transmedia terms, 
from fiction to documentary, through journalism, advertising and political communication" (Scolari, 2014). Regarding the audiovisual industry, for example, "transmedia" has become the "magic word" of any project; in fact, "in some moments it seems as if something could not be done in a single medium" (Tubau, 2011).

The literary system has also integrated transmedia as an element or an aesthetic process. The story, but also a similar aesthetic, rhetoric or theme, extend beyond the margins of the literary text to other media, each of which does not lose its autonomy and specificity. In turn, transmedia also articulates "modes of reciprocal and procedural affectation between media, languages and technologies", which strongly destabilize their origin spaces (Kozak, 2015): literary texts, which often function as start windows, change in the transmedia process.

The following article will analyzed how transmedia functions in two contemporary novels written in Spanish: La muerte me da (2007), by Mexican author Cristina Rivera Garza; and Alba Cromm (2010), by Spanish author Vicente Luis Mora. In addition to describing the transmedia system, the article will emphasized on how transmedia establishes as a core component in the conformation of the novels' heroines.

Key words: Transmedia - Transmedia Storytelling - Technological Narratives - Digital Writing - Blogs - 21st Century Literature - Mexican Literature - Spanish Literature Rivera Garza - Mora

Resumo: Nos últimos anos, a cada vez mais projetos, objetos, programas, artefatos, obras, textos pertencentes à esfera cultural possuem, em alguma ou em todas as etapas do processo produtivo, algum componente transmedial. Praticamente, não ficam atores da cultura e a comunicação "que não estejam a pensar sua produção em termos transmediáticos, desde a ficção até o documentário, passando pelo jornalismo, a publicidade e a comunicação política" (Scolari, 2014). Relativo à indústria audiovisual, por exemplo, "transmídia" converteu-se na "palavra mágica" de qualquer projecto em media ou grande escala; de facto, "em alguns momentos parece como se já não se pudesse fazer algo que se desenvolva num único meio" (Tubau, 2011).

O sistema da literatura, por sua vez, também tem integrado à transmidialidade como um elemento ou processo estético mais. O relato, mas também uma mesma estética, retórica ou temática, se estendem para além das margens do texto literário para outros meios, a cada um dos quais não perde sua autonomia e especificidade. A sua vez, na transmidialidade também se articulam "modos de afetação recíproca e procesual entre meios, linguagens e tecnologias", os quais desestabilizam fortemente seus espaços de origem (Kozak, 2015): os textos literários, que muitas vezes funcionam como janelas de início, resultam transformados no processo transmídia.

No seguinte artigo, a transmidialidade será analisada em duas novelas contemporâneas em espanhol: A morte dá-me (2007), da mexicana Cristina Rivera Garza; e Alba Cromm (2010), do espanhol Vicente Luis Mora. Além de detalhar o funcionamento do processo transmídia, uma ênfase especial será colocada em como isso é estabelecido como um componente na formação das heroínas das histórias. 
Palavras chave: Transmedialidade - Narrativas Transmídia - Narrativas Tecnológicas - Escrituras Digitais - Blogs - Literatura do Século 21 - Literatura Mexicana - Literatura Espanhola - Rivera Garza - Mora

[Las traducciones de los abstracts fueron supervisadas por el autor de cada artículo] 